\title{
Incidence of pain after inguinal hernia repair in the elderly. A retrospective historical cohort evaluation of 18-years' experience with a mesh \& plug inguinal hernia repair method on about 3000 patients
}

\author{
Marcello Donati ${ }^{2 *}$, Giovanna Brancato ${ }^{1}$, Angelita Giglio ${ }^{1}$, Antonio Biondi ${ }^{2}$, Francesco Basile ${ }^{2}$, Angelo Donati ${ }^{1}$
}

From 26th National Congress of the Italian Society of Geriatric Surgery

Naples, Italy. 19-22 June 2013

\begin{abstract}
Background: Chronic pain after prosthetic inguinal hernioplasty is one of the most important current issues in the current literature debate. Mechanisms related to pain development are only partially known. Influence of age as well as other factors is still unclear. The aim of this work was to evaluate whether development of chronic pain after open prosthetic plug and mesh inguinal hernioplasty is influenced by age.

Methods: Analysis was retrospectively conducted, dividing our cohort of patients $(2,902)$ who had undergone prosthetic open plug\&mesh inguinal hernioplasty from Jannuary 1994 to May 2012, following only the age criterion (cut-off 65 yrs.), into two groups (Gr.A<65 yrs, Gr.B>65 yrs.). All patients were routinely submitted to a postoperative questionnaire. Complications such as analgesic assumption were registered in both groups. Pain intensity was classified following the Visual Analogic Scale (VAS). Incidence of chronic pain, discomfort, and numbness, was assessed in both groups. Statistical significance was assessed by $\mathrm{X}_{2}$-test.
\end{abstract}

Results: Only $0.2 \%$ of patients suffered from a recurrence in our cohort. Postoperative chronic pain was observed in Gr. A in $0.12 \%$ of patients vs Gr.B $0.09 \%$ ( $p>0.05$ ). Incidence of other postoperative symptoms such as discomfort or numbness were slightly prevalent on young patients (respectively $p=0.0286$ and $p=0.01$ ), while for hyperesthesia and sensation of foreign body no statistically significant difference of incidence between groups was observed.

Conclusions: Real chronic pain after inguinal hernioplasty is a rare clinical entity. Other causes of chronic pain should be accurately researched and excluded. In young patients psychological factors seem to show a slight influence. There was no influence of age on chronic postoperative pain incidence after inguinal hernioplasty.

\section{Background}

Chronic pain after prosthetic inguinal hernia repair is considered to be one of the unsolved problems after prosthetic inguinal hernioplsty $[1,2]$. Its incidence is referred to be from 0.03 to $31 \%$ in the scientific literature $[3,4]$ (Table 1) many different mechanisms have been advocated to explain chronic pain after inguinal

\footnotetext{
* Correspondence: mdonati@unict.it

${ }^{2}$ Department of Surgery, General and Oncologic Surgery Unit, Vittorio-

Emanuele University Hospital of Catania, Italy

Full list of author information is available at the end of the article
}

hernioplasty, and consequently different surgical solutions have also been proposed [5]. The aim of this work was to show the influence of age on incidence of postoperatively chronic pain after open prosthetic inguinal hernia repair in older patients (over 65 yrs.) retrospectively analyzing our single center 18 year experience with a published original mesh and plug technique [6,7] on 2902 consecutively operated patients. 
Table 1 Incidence of groin pain after inguinal hernioplasty reported in the literature

\begin{tabular}{|c|c|c|c|c|c|}
\hline Author & Year & Journal & $\mathrm{N}^{\circ}$ cases & Followed up & Chronic Pain (\%) \\
\hline Amid PK & 1996 & Eur J Surg & 4000 & 3480 & $0.03 \%$ \\
\hline Negro P & 2000 & Chir Ital & 839 & 764 & $0.9 \%$ \\
\hline Courtney CA & 2002 & Br J Surg & 5506 & 4062 & $3 \%$ \\
\hline Heikkinen T & 2004 & Surg Endosc & 61 & 59 & $7 \%$ \\
\hline Benedetti M & 2005 & Hernia & 685 & $?$ & $11.9 \%$ \\
\hline Haapaniemi S & 2002 & Eur J Surg & 272 & 223 & $15 \%$ \\
\hline Leardi S & 2003 & Chir Ital & 100 & 60 & $25 \%$ \\
\hline Callesen $T$ & 1999 & Br J Surg & 466 & 419 & $25 \%$ \\
\hline Kumar S & 2002 & Br J Surg & 560 & 454 & $30 \%$ \\
\hline Koninger J & 2004 & Langenbecks Arch Surg & 93 & 76 & $31 \%$ \\
\hline Inaba T & 2012 & Surg Today & 219 & 191 & $14.7 \%$ \\
\hline Birk D & 2013 & Hernia & 220 & 220 & $1.2 \%$ \\
\hline Bittner R & 2011 & World J Surg & 300 & 300 & $3 \%$ \\
\hline Bright E & 2010 & World J Surg & 9607 & $?$ & $4.9 \%$ \\
\hline
\end{tabular}

\section{Materials and methods}

From January 1994 to May 2012, in our unit, 2902 patients were submitted to an open prosthetic inguinal hernioplasty for primary inguinal hernia following our previously described plug and mesh procedure [6,7]. Most of them received the surgical treatment in a day surgery setting $[8,9]$ as for other kind of hernias in our center $[10,11]$. They were 2752 males (94.5\%) and 150 females (5.5\%).

All patients were preoperatively informed about the procedure, anesthesia, intraoperative feelings or sensation during surgical manipulation and postoperative care as previously described $[8,9]$. We divided the above mentioned collective into 2 Groups based on age: group A (<65 yrs: 1795 patients) and group B(>65 yrs:1107 patients). Group A showed a comorbidities in only about $44.8 \%(805 / 1795)$ of patients. While in group B 938 patients showed comorbidities (84.7\%), 478 (50.9\%) of them showing were relevant (ASA III-IV) (Table 2).

Comorbidities of both groups are summarized in table 2 . All patients underwent the above mentioned surgical procedure, most of them under local anesthesia (as showed in Table 3), following renowned and well described methods used by our group for many years also for other kinds of hernias [12,13].

Table 2 Patients comorbidities in both groups

\begin{tabular}{lcc}
\hline & $\begin{array}{c}\text { Group A < } \\
\text { (1795 } \mathbf{~} \text { } \mathbf{~ y r s . )}\end{array}$ & $\begin{array}{c}\text { Group B >65 } \text { yrs. } \\
\text { (1 107 } \mathbf{~ p t s . )}\end{array}$ \\
\hline Cardiovascular & 437 & 449 \\
Respiratory & 122 & 131 \\
Metabolic & 105 & 102 \\
Hematologic & 41 & 8 \\
Neurologic & 38 & 7 \\
Others & 62 & 241 \\
Total & 805 & 938 \\
& (44.8\% of cohort) & (84.7\% of cohort) \\
\hline
\end{tabular}

Groups were evaluated for incidence of postoperative (defined as up to 12 postoperative day) and delayed (chronic) pain after inguinal hernioplasty as well as other sensations/complains such as referred numbness, discomfort, hyperestesia, sensation of foreign body.

The operation was conducted under local, spinal and general anesthesia in Group A respectively in 98.8\%,0 and $1.2 \%$ of patients, while in Group B in $97.5 \%, 1 \%$ and $1.5 \%$. No statistically significant differences regarding distribution of patients in local general and spinal anesthesia were found between the 2 groups (Table 3 ).

Patients were asked about pain intensity on postoperative recovery and during follow-up checks by using a Visual Analogic Scale (VAS). Then we followed-up the patients for the about 2 weeks after the operation, by collecting data about daily activities, referred pain during the daily activities, type of pain, duration of pain, assumption of painkillers. Pain intensity when present was classified following the Visual Analogic Scale (VAS) of Glasgow ranging from $0-10$, as previously used in other reports $[10,14]$. All patients were clinically evaluated together with an ultrasound follow-up after 3 months and after 1 year [15], in order to establish presence of recurrence, ask residual pain, other minor symptoms (like numbness, hyperestesia etc..etc..) and eventually chronic pain (we defined chronic pain as the presence of pain for more

Table 3 Type of anesthesia for herniorrhaphy and day surgery distribution in both groups

\begin{tabular}{lcc}
\hline & $\begin{array}{c}\text { Group A <65 yrs. } \\
\text { (1795 pts.) }\end{array}$ & $\begin{array}{c}\text { Group B }>\mathbf{6 5} \text { yrs. } \\
\mathbf{( 1 1 0 7} \mathbf{~ p t s . )}\end{array}$ \\
\hline Local Anesthesia & $1775(98.8 \%)$ & $1081(97.5 \%)$ \\
Spinal Anesthesia & 0 & $11(1 \%)$ \\
General Anesthesia & $20(1.2 \%)$ & $16(\sim 1.5 \%)$ \\
Day Surgery & $1730(96.4 \%)$ & $889(80.3 \%)$ \\
\hline
\end{tabular}


than 6 months after the operation). All differences were statistically evaluated through the $\mathrm{X}_{2}$-test for significance $(p<0.05)$.

\section{Results}

We had a total of 6 recurrences $(0.2 \%)$ in our cohort: 4 really inguinal hernia recurrences and 2 pseudorecurrences as 2 becoming symptomatic after hernioplasty (misdiagnosed hernias).

In group A $57.2 \%$ of patients used analgesia during recovery and 36.9 at home while in group B respectively 48.2 and $34.3 \%$.

After one year In group A no more pts referred light pain in both groups, rarely they referred mild pain (VAS 4-7) without differences between young and old patients, so like for strong chronic pain (VAS 8-10). Minor symptoms like discomfort and numbness showed a slight prevalence on Gr.A in front of Gr.B after one year $(p=0.0286$ and 0.01). Table 4.

During recovery in group A early postoperative pain till 2 weeks, was more often observed than in group B: $17.1 \%$ vs $14.1 \% p=0.009$. While delayed postoperative pain and chronic pain showed no significance on incidence in both groups: $p=0.64$ and $p=0.836$ (Table 5). Also for intermittent and rare pain (often due to changes in humidity) no differences weres found $p=0.136$. A total of 7 patients in the collective of patients complained middle pain whil only 3 strong pain. In this 3 of a vertebral compression or coxo-femoral arthrosis was identified as a secondary cause of inguinal pain by MRI, and they were consequently treated. The other 7 patients reporting middle pain (VAS 4-7) referred a progressive relief/reduction of symptoms not hesitating to begin with legal proceedings, were treated conservatively without any exploration of the groin but with local infiltration of local anesthetic drugs.

Table 4 Distribution of symptoms in both groups after 1 year

\begin{tabular}{lccc}
\hline & $\begin{array}{c}\text { Group A <65 yrs. } \\
\text { (1795 pts.) }\end{array}$ & $\begin{array}{c}\text { Group B >65 yrs. } \\
\text { (1107 pts.) }\end{array}$ & $p$ \\
\hline Discomfort & $308(17.1 \%)$ & $156(14.1 \%)$ & $\mathbf{0 . 0 2 8 6}$ \\
Foreign Body Sensation & $215(11.9 \%)$ & $132(12 \%)$ & 0.965 \\
Numbness & $157(8.7 \%)$ & $68(6.1 \%)$ & $\mathbf{0 . 0 1}$ \\
Hyperesthesia & $130(7.2 \%)$ & $70(6.3 \%)$ & 0.34 \\
Burns & 0 & 0 & - \\
Light pain* & 0 & 0 & - \\
Mild Pain** & $5(0.28 \%)$ & $2(0.18 \%)$ & 0.6 \\
Strong Pain*** & $2(0.12 \%)$ & $1(0.09 \%)$ & 0.8 \\
\hline VAS=Visual Analogic Scale. Pain is here intended to be continous. & \\
* 0-3 in VAS & & & \\
** 4-7 in VAS & & & \\
***-10 in VAS & &
\end{tabular}

\section{Discussion}

Chronic pain after inguinal hernioplasty can be defined as a persistent pain in operated groin region, lasting from 6 months after reoperation until at least one year, following EHS guidelines definition [1,16]. Of course for patients post-hernioplasty pain begins after the operation and they have fear to have a chronicization of pain, when its duration is more then one week. However, previous studies have shown the influence of many factors.

The incidence in world literature is estimated between $1-31 \%$ (Table 1). This large range maybe reflects heterogeneity of surgical approaches and techniques, duration of follow-up and interpretation of data such as referred symptoms from each Author.

Factors related to surgical techniques, psychological factors [17], patients' fear, and open or laparoscopic approach were previously analyzed to assess the influence on postoperative chronic pain[1]. Mechanisms (nerve entrapment, nerve trauma, amputation neurinoma, cicatrization damage) were advocated responsible for chronic pain after inguinal hernioplasty and were previously investigated in other papers [2]. The real incidence of chronic pain is lower than usually reported, discrepancies in published data are mainly due to the definition of "pain". Most patients' complaints are really just discomfort and also in our experience, as elsewhere reported, really severe chronic pain is extremely rare [18]. In previous publications other authors reported the influence of age as a risk factor for developing chronic inguinal pain after hernioplasty $[1,19,20]$. Even if to date, to our knowledge, no specific studies have been published assessing the influence of age alone on post-herniorrhaphy chronic pain, it is commonly accepted that young age is a risk factor for chronic pain [16]. In our retrospective analysis we could not confirm such previous findings; on the contrary we found there was no statistical significance in the difference between our two groups (younger and older patients) except for early postoperative pain. In young patients a little prevalence of minor symptoms like numbness or discomfort was also found, this could

\section{Table 5 Temporally-related distribution of pain in both} groups

\begin{tabular}{cccc}
\hline & $\begin{array}{c}\text { Group A } \\
<65 \text { yrs. } \\
(\mathbf{1 7 9 5} \text { pts.) }\end{array}$ & $\begin{array}{c}\text { Group B } \\
>\mathbf{6 5} \text { yrs. } \\
(\mathbf{1 1 0 7} \text { pts.) }\end{array}$ & $p$ \\
\hline Early postoperative pain* (VAS>4) & 484 & 251 & $\mathbf{0 . 0 0 9}$ \\
& $(26.9 \%)$ & $(22.6 \%)$ & \\
Postoperative pain (after 2 weeks & 287 & 149 & 0.064 \\
until 30 days) (VAS $>4)$ & $(16 \%)$ & $(13.4 \%)$ & \\
Rare pain (not continous) (VAS<4) & 628 & 418 & 0.136 \\
(after 6 months) & $(34.9 \%)$ & $(37.7 \%)$ & \\
Chronic pain (continous) & 2 pts. & 1 pts. & 0.837 \\
(VAS $>7)$ (after 6 months) & $(0.12 \%)$ & $(0.09 \%)$ & \\
\hline
\end{tabular}

* any pain despite analgesics assumption. 
maybe related to a more active life and also to psycologi$\mathrm{cal} / \mathrm{emotional}$ reasons. We interpreted these findings with the idea that maybe other factors, rather than age, have a greater influence on triggering chronic pain. As we stated in other papers, our surgical method presupposes identification and preservation of all three nerves of the inguinal region (Ileo-inguinal, ileo-ipogastric and genito-femoral). As reported in a previous study the preventive identification of all three nerves is a factor reducing the risk of post-operative chronic pain [21,22]. Another study reported controversial data about this issue, while Amid confirmed that the identification of structures is the first preventive factor to avoid post-operative complications [23]. Even other technical details such as mesh fixation showed an influence on pain. The TIMELI trial has shown a reduced risk of post chronic pain by using fibrin sealant as a fixation method of mesh instead of common stitches [24], this was also confirmed in a recent metanalysis [25]. Even the approach (open or laparoscopic) has been advocated as a risk factor for chronic pain [26,27], however, there are same data in contrast with this assumption [28] especially in laparoscopic techniques, mesh fixation methods seem to be of capital importance $[29,30]$. Our technique does not fix the mesh to the abdominal wall as it is self-adhesive, this could explain the low incidence of post-operative chronic pain [31].

Mesh weight was also introduced as a risk factor for development of chronic pain, thus light-weight meshes were introduced to reduce it [32]. However, further studies have shown that even if early pain is reduced by light-weight meshes, in long term follow-ups this difference is reduced [33]. A recent study has shown no influence of mesh weight in the incidence of chronic pain when the operating surgeon and the surgical technique are the same [34]. Preventive resection of all three nerves was also proposed $[35,36]$ even if its effectiveness in combination with open mesh procedures remains questionable [37].

Over time (more than 10 years) patients tend to refer pain tolerance until disappearance or relief of symptoms [38]. Thus in cases of light-mild pain a surgical exploration could be avoided. Minimal contact between mesh and nerves, use of self-adhesive meshes, routine identification of nerves, a correct pre-operative flow-chart excluding other causes of inguinodynia, psychological pre-operative care of patients with detailed information about the operation could explain the low chronic pain rates in our series.

Treatment methods in literature range from local drug infiltration using desametasone or steroid-like drugs to anesthetics such as bupivacain [39]. Radiofrequency ablation of nerves was also described and tested [40]. Laser therapy such as TENS was also tested as well as physical therapy. Surgical exploration of the groin with excision of all three nerves (neurectomy) [41] is intended to be the "ultima ratio" of treatment and has been effective in many series [42-44], even if in longterm follow-up a relapse of symptoms is possible in a not insignificant percentage of patients [45-48]. In our series it was not necessary to surgically manage chronic pain. All three patients complaining strong pain obtained relief of symptoms after undergoing a vertebro-lumbar operation for discal hernia or orthopedic operation for coxo-femoral arthrosis diagnosed after inguinal hernia repair by an additional diagnostic flowchart. The other group experiencing middle pain, knowed a progressive reduction of symptoms over time.

\section{Conclusions}

In conclusion our data show that age is not a risk factor to developing chronic inguinal pain after hernioplasty. Real chronic pain is to be considered a rare entity. Unfortunately a heterogeneous group of other sensations more frequently affects patients after prosthetic inguinal hernioplasty, not really affecting daily activities and quality of life. Other causes of chronic pain should be carefully excluded before defining symptoms as chronic pain after hernioplasty.

Even if pain in younger patients has the same incidence as in older patients, in younger patients it is less well tolerated and they are prone to a greater analgesic assumption, additionally early postoperative pain in younger patient is more frequent. In the elderly all other sensations are better tolerated. A precise surgical technique, with systematic identification and preservation of inguinal region nerves, should be considered an important factor to prevent chronic pain. A conservative treatment, in many cases, is possible, surgical re-exploration of the groin with total neurectomy of all three nerves should be carefully considered as "extrema ratio" of treatment.

\section{Authors information}

MD: Assistant Professor of Surgery at University of Catania. GB: Associate Professor of Surgery at University of Catania. AG: Resident in General Surgery at University of Catania. AB: Associate Professor of Surgery at University of Catania. FB: Full Professor of Surgery at University of Catania. AD: Full Professor of Surgery at University of Catania.

\footnotetext{
List of abbreviations used

VAS (Visual Analogic Scale); MRI (Magnetic Resonance Imaging); EHS (European Hernia Society); TENS (Transcutaneous Electrical Nerve
} Stimulation).

\section{Competing interests}

The Authors have no conflict of interests. The Authors received no financial support for the present study. 


\section{Authors' contributions}

MD:designed the study, co-collected data, wrote the paper, made literature research, gave final approval of the version to be published. GB: co-wrote the paper and co-made literature research, gave final approval of the version to be published. AG: collected and interpreted data, gave final approval of the version to be published. AB: co-collected data and draft tables, gave final approval of the version to be published. FB: made finale revisions, gave final style to the paper, gave final approval of the version to be published. AD: conception and co-designed of the study, made revisions, gave final style to the paper, gave final approval of the version to be published.

\section{Declarations}

Funding of this article came from University funds.

This article has been published as part of BMC Surgery Volume 13 Supplement 2, 2013: Proceedings from the 26th National Congress of the Italian Society of Geriatric Surgery. The full contents of the supplement are available online at http://www.biomedcentral.com/bmcsurg/supplements/13/S2

\section{Authors' details}

'Department of Surgical Sciences, Organ Transplants and New Technologies, General Surgery and Week Hospital Unit, University Hospital of Catania, Italy. ${ }^{2}$ Department of Surgery, General and Oncologic Surgery Unit, VittorioEmanuele University Hospital of Catania, Italy.

Published: 8 October 2013

\section{References}

1. Campanelli G, Bertocchi V, Cavalli M, Bombini G, Biondi A, Tentorio T, Sfeclan C, Canziani M: Surgical treatment of chronic pain after inguinal hernia repair. Hernia 2013, Mar 22.

2. Heise $C P$, Starling JR: Mesh inguinodynia:a new clinical syndrome after inguinal herniorrhaphy? J Am Coll Surg 1998, 187(5):514-8.

3. Amid PK, Shulman AG, Lichtenstein IL: Open "tension-free" repair of inguinal hernias: the Lichtenstein technique. Eur J Surg 1996, 162(6):447-53.

4. Köninger J, Redecke J, Butters M: Chronic pain after hernia repair:a randomized trial comparing Schouldice, Lichtenstein and TAPP. Langenbecks Arch Surg 2004, 389(5):361-5.

5. Birk D, Hess S, Garcia-Pardo C: Low recurrence rate and low chronic pain associated with inguinal hernia repair by laparoscopic placement of Parietex ProGrip ${ }^{\mathrm{TM}}$ mesh: clinical outcomes of 220 hernias with mean follow-up at 23 months. Hernia 2013, Feb 15.

6. Donati A, Privitera A, Brancato G, Donati M, Cardi F: Ann It Chir 2000, 71(5):615-20, [Inguinal hernioplasty with calibrated prosthesis (personal modification of the Trabucco technique].

7. Donati M, Brancato G, Puglia S, Donati A: The extraperitoneal prosthetic repair of abdominal wall defects in the elderly. BMC Geriatrics 2010, 10(Suppl 1):A6.

8. Zanghì G, Brancato G, Privitera A, Rinaldi E, Donati M: Ann Ital Chir 1998, 69(5):563-74, [Organizational and surgical-technical aspects of the service of abdominal hernioplasty].

9. Brancato G, Donati M, Gandolfo L, Privitera A, Cavallaro G: Chir Ital 2003, 55(1):65-71, [Organization of a day surgery unit for hernia].

10. Donati M, Gandolfo L, Brancato G, Privitera A, Donati A: Day Hospital for Incisional Hernia Repair: Selection Criteria. Acta Chir Belg 2008, 108(2):198-202.

11. Donati M, Gandolfo L, Privitera A, Cavallaro G, Brancato G: Chir Ital 2003, 55(4):609-15, [Inguinal hernia recurrence after prosthetic repair: our experience].

12. Brancato G, Privitera A, Gandolfo L, Donati M, Caglià P: Minerva Chir 2002, 57(1):13-6, [Plug-technique for umbilical hernia repair in the adult].

13. Donati $\mathrm{M}$, Brancato $\mathrm{G}$, Donati $\mathrm{A}$ : Open incisional hernia repair in local anaesthesia. Acta Chir Belg 2010, 110(1):45-50.

14. Privitera A, Donati M, Gandolfo L, Brancato G: Analogic evaluation of pain during inguinal hernioplasty under local anaesthesia. Ann Ital Chir 2003, 74(4):463-66.

15. Gandolfo L, Donati M, Privitera A, Palmeri S, Brancato G: Chir Ital 2007, 59(6):835-41, [Ultrasound tissue modifications after polypropylene prosthesis apposition in inguinal hernia].

16. Simons MP, Aufenacker T, Bay-Nielsen M, Bouillot JL, Campanelli G, Conze J, de Lange D, Fortelny R, Heikkinen T, Kingsnorth A, Kukleta J, MoralesConde S, Nordin P, Schumpelick V, Smedberg S, Smietanski M, Weber G,
Miserez M: European Hernia Society guidelines on the treatment of inguinal hernia in adult patients. Hernia 2009, 13:343-403.

17. Powell R, Johnston M, Smith WC, King PM, Chambers WA, Krukowski Z, McKee L, Bruce J: Psychological risk factors for chronic post-surgical pain after inguinal hernia repair surgery: a prospective cohort study. Eur J Pain 2012, 16(4):600-10.

18. Inaba T, Okinaga K, Fukushima R, Ikeda Y, Yamazaki E, Koide T, Horikawa M, Inoue T, Ogawa E: Chronic pain and discomfort after inguinal hernia repair. Surg Today 2012, 42(9):825-9.

19. Kalliomäki ML, Meyerson J, Gunnarsson U, Gordh T, Sandblom G: Longterm pain after inguinal hernia repair in a population-based cohort; risk factors and interference with daily activities. Eur J Pain 2008, 12(2):214-25, Epub 2007 Jul 2.

20. Fränneby U, Sandblom G, Nordin P, Nyrén O, Gunnarsson U: Risk factors for long-term pain after hernia surgery. Ann Surg 2006, 244(2):212-9.

21. Bischoff JM, Aasvang EK, Kehlet $H$, Werner MU: Does nerve identification during open inguinal herniorrhaphy reduce the risk of nerve damage and persistent pain? Hernia 2012, 16(5):573-7.

22. Alfieri S, Rotondi F, Di Giorgio A, Fumagalli U, Salzano A, Di Miceli D, Ridolfini MP, Sgagari A, Doglietto G: Groin Pain Trial Group. Influence on preservation versus division of ilioinguinal, iliohypogastric and genital nerves during open mesh herniorrhaphy: a prospective multicentric study. Ann Surg 2006, 243:553-8.

23. Amid PK, Hiatt JR: New understanding of the causes and surgical treatment of postherniorrhaphy inguinodynia and orchalgia. J Am Coll Surg 2007, 205:381-385.

24. Campanelli G, Pascual MH, Hoeferlin A, Rosenberg J, Champault G, Kingsnorth A, Miserez M: Randomized, controlled, blinded trial of Tisseel/ Tissucol for mesh fixation in patients undergoing Lichtenstein technique for primary inguinal hernia repair: results of the TIMELI trial. Ann Surg 2012, 255(4):650-7.

25. de Goede B, Klitsie PJ, van Kempen BJ, Timmermans L, Jeekel J, Kazemier G, Lange JF: Meta-analysis of glue versus sutured mesh fixation for Lichtenstein inguinal hernia repair. Br J Surg 2013, 100(6):735-42.

26. O'Reilly EA, Burke JP, O'Connell PR: A meta-analysis of surgical morbidity and recurrence after laparoscopic and open repair of primary unilateral inguinal hernia. Ann Surg 2012, 255(5):846-53.

27. Singh AN, Bansal VK, Misra MC, Kumar S, Rajeshwari S, Kumar A, Sagar R, Kumar A: Testicular functions, chronic groin pain, and quality of life after laparoscopic and open mesh repair of inguinal hernia: a prospective randomized controlled trial. Surg Endosc 2012, 26(5):1304-17.

28. Bright E, Reddy VM, Wallace D, Garcea G, Dennison AR: The Incidence and Success of Treatment for Severe Chronic Groin Pain After Open, Transabdominal Preperitoneal, and Totally Extraperitoneal Hernia Repair. World J Surg 2010, Feb 4.

29. Brügger L, Bloesch M, Ipaktchi R, Kurmann A, Candinas D, Beldi G Objective hypoesthesia and pain after transabdominal preperitoneal hernioplasty: a prospective, randomized study comparing tissue adhesive versus spiral tacks. Surg Endosc 2012, 26(4):1079-85.

30. Fortelny RH, Petter-Puchner AH, May C, Jaksch W, Benesch T, Khakpour Z, Redl H, Glaser KS: The impact of atraumatic fibrin sealant vs. staple mesh fixation in TAPP hernia repair on chronic pain and quality of life: results of a randomized controlled study. Surg Endosc 2012, 26(1):249-54.

31. Quyn AJ, Weatherhead KM, Daniel T: Chronic pain after open inguinal hernia surgery: suture fixation versus self-adhesive mesh repair. Langenbecks Arch Surg 2012, 397(8):1215-8.

32. O'Dwyer PJ, Kingsnorth AN, Molloy RG, Small PK, Lammers B, Horeyseck G: Randomized clinical trial assesing impact of a lightweight or heavyweight mesh on chronic pain after inguinal hernia repair. $\mathrm{Br} J$ Surg 2005, 92(2):166-70.

33. Weyhe D, Belyaev O, Müller C, Meurer K, Bauer KH, Papapostolou G, Uhl W: Improving outcomes in hernia repair by the use of light meshes-a comparison of different implant constructions based on a critical appraisal of the literature. World J Surg 2007, 31(1):234-44.

34. Paajanen $H$, Rönkä $K$, Laurema A: A single-surgeon randomized trial comparing three meshes in lichtenstein hernia repair: 2- and 5-year outcome of recurrences and chronic pain. Int I Surg 2013, 11(1):81-4.

35. Hakeem A, Shanmugam V: Effectiveness of multiple neurectomies to prevent chronic groin pain after tension-free hernia repair. Int Surg 2011, 96(2):162-3. 
36. Johner A, Faulds J, Wiseman SM: Planned ilioinguinal nerve excision for prevention of chronic pain after inguinal hernia repair: a meta-analysis. Surgery 2011, 150(3):534-41.

37. Reinpold WM, Nehls J, Eggert A: Nerve management and chronic pain after open inguinal hernia repair: a prospective two phase study. Ann Surg 2011, 254(1):163-8.

38. van Veen RN, Wijsmuller AR, Vrijland WW, Hop WC, Lange JF, Jeekel J: Randomized clinical trial of mesh versus non-mesh primary inguinal hernia repair: long-term chronic pain at 10 years. Surgery 2007, 142(5):695-8.

39. Kastler A, Aubry S, Piccand V, Hadjidekov G, Tiberghien F, Kastler B: Radiofrequency neurolysis versus local nerve infiltration in 42 patients with refractory chronic inguinal neuralgia. Pain Physician 2012, 15(3):237-44.

40. Amid PK: A 1-stage surgical treatment for postherniorraphy neuropathic pain:triple neurectomy and proximal end implantation without mobilization of the cord. Arch Surg 2002, 137:100-104.

41. Thomassen I, van Suijlekom JA, van de Gaag A, Ponten JE, Nienhuijs SW: Ultrasound-guided ilioinguinal/iliohypogastric nerve blocks for chronic pain after inguinal hernia repair. Hernia 2012, Sep 27.

42. Amid PK, Chen DC: Surgical treatment of chronic groin and testicular pain after laparoscopic and open preperitoneal inguinal hernia repair. $J$ Am Coll Surg 2011, 213(4):531-6.

43. Kline CM, Lucas CE, Ledgerwood AM: Directed neurectomy for treatment of chronic postsurgical neuropathic pain. Am J Surg 2013, 205(3):246-8.

44. Fortelny RH, Petter Puchner AH: A method for the reduction of chronic pain after tension-free repair of inguinal hernia: iliohypogastric neurectomy and subcutaneous transposition of the spermatic cord. Hernia 2010, 14(2):229-30.

45. Zacest AC, Magill ST, Anderson VC, Burchiel KJ: Long-term outcome following ilioinguinal neurectomu for chronic pain. I Neurosurg 2009, Sep 25.

46. Amato $B$, Compagna $R$, et al: Feasibility of inguinal hernioplasty under local anesthesia in elderly patients. BMC Surg 2012, 12(Suppl 1):S2.

47. Compagna R, Vigliotti G, Coretti G, Amato M, Aprea G, Puzziello A, Militello C, Amato B: Comparative study between levobupivacaine and bupivacaine for hernia surgery in the elderly. BMC Surgery 2012, 12(Suppl.1):S12.

48. Amato B, Moja L, Panico S: Shouldice technique versus other open techniques for inguinal hernia repair. Cochrane database of systematic reviews (online) 2012, 4:CD001543.

doi:10.1186/1471-2482-13-S2-S19

Cite this article as: Donati et al: Incidence of pain after inguinal hernia repair in the elderly. A retrospective historical cohort evaluation of $18-$ years' experience with a mesh \& plug inguinal hernia repair method on about 3000 patients. BMC Surgery 2013 13(Suppl 2):S19.

\section{Submit your next manuscript to BioMed Central and take full advantage of:}

- Convenient online submission

- Thorough peer review

- No space constraints or color figure charges

- Immediate publication on acceptance

- Inclusion in PubMed, CAS, Scopus and Google Scholar

- Research which is freely available for redistribution

Submit your manuscript at www.biomedcentral.com/submit
Biomed Central 